\title{
TRANSPLANT RENAL ARTER STENOZU: TEK MERKEZ DENEYIMI
}

\author{
TRANSPLANT RENAL ARTERY STENOSIS: SINGLE CENTER EXPERIENCE
}

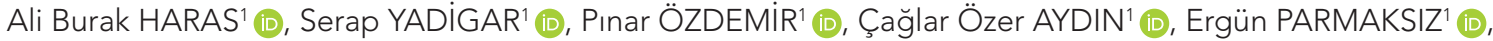 \\ Meral MEŞE ${ }^{1}$ D, Serkan Feyyaz YALIN ${ }^{1}$ iD, Zerrin BiCiK BAHÇEBAŞI ${ }^{1}$ iD
}

1Sağlık Bilimleri Üniversitesi Kartal Dr. Lütfi Kırdar Eğitim ve Araştırma Hastanesi, Nefroloji Kliniği, İstanbul, Türkiye

ORCID IDs of the authors: A.B.H. 0000-0001-8779-5421; S.Y. 0000-0002-3156-4883; P.Ö. 0000-0002-8456-713X; Ç.Ö.A. 0000-0003-1218-7506; E.P. 0000-0002-9009-376X; M.M. 0000-0002-6104-2058; S.F.Y. 0000-0002-8146-6966; Z.B.B. 0000-0003-4740-2333

Cite this article as: Haras AB, Yadigar S, Ozdemir P, Aydin CO, Parmaksiz E, Mese M, Yalin SF, Bicik-Bahcebasi Z. Transplant renal artery stenosis: single center experience. J Ist Faculty Med 2020;83(1):55-9. doi: 10.26650/IUITFD.2019.0032

\section{ÖZET}

Amaç: Transplant renal arter stenozu (TRAS) ve posttransplant arterial hipertansiyon allograft disfonksiyon ve greft kaybının tedavi edilebilir bir nedenidir. TRAS gelişiminde risk faktörleri arasında donor yaşı, uzun sureli gecikmiş greft fonksiyonu, soğuk iskemi süresi, eşzamanlı CMV enfeksiyonu varlığı ve cerrahi teknik vardır. Perkütan Translüminal Anjioplasti (PTA) \%60-90 vakada renal perfüzyonu sağlar. Bu çalışmamızda, kliniğimizdeki 6 TRAS vakasının özelliklerini inceledik.

Gereç ve Yöntem: Kliniğimizde, 2017 yılında böbrek nakli yapılan hastalar tıbbi kayıtlardan inceledik. TRAS gelişen hastaların yaş, cinsiyet, nakil sırasındaki diğer bulguları ve demografik özellikleri kaydedildi.

Bulgular: Yirmi altı vakanın altısında TRAS saptandı. Iliak arter darlık varlığı ile birlikte renal arter stenozu olan 2 hastada CMV PCR pozitifliği saptandı. Hastalara PTA ve stent implantasyonu uygulandı. Takiplerde antihipertansif tedavi ihtiyacı azaldı.

Sonuç: TRAS, böbrek nakli sonrasında allograft disfonksiyonun nedenlerinden biridir. Sonuç olarak allograft disfonksiyonda akılda tutulmalıdır. Diğer risk fatörlerine ek olarak, cerrahi teknik de TRAS gelişiminde önemli bir rol oynar. Greft fonksiyonu erken girişimle korunabilir.

Anahtar Kelimeler: Allograft disfonksiyonu, hipertansiyon, transplant renal arter stenozu

\begin{abstract}
Objective: Transplant renal artery stenosis (TRAS) and post-transplant arterial hypertension is a treatable cause of allograft dysfunction and graft loss. The risk factors for the development of TRAS include: donor age, prolonged and delayed graft function, cold ischemia time, concomitant CMV infection and surgical technique. Percutaneous transluminal angioplasty (PTA) has proven successful in treating TRAS in $60-90 \%$ of cases by providing renal reperfusion. In this study,we evaluated six TRAS cases in our clinic.

Material and Method: We evaluated patients retrospectively from medical records who underwent transplantation in 2017 We recorded the age, gender, creatinine, other findings during transplantation, and the demographic features of transplant patients with TRAS.

Results: TRAS was reported in 6 of 26 cases. The presence of iliac artery stenosis associated with renal artery stenosis was seen in two patients with CMV PCR (+). Patients underwent PTA and stent implantation. The need for antihypertensive treatment of the patients lessened during follow-up.

Conclusion: TRAS is one of the reasons for allograft dysfunction after kidney transplantation. For this reason it should be kept in mind when determining the cause of the allograft disfunction. In addition to other risk factors, surgical technique plays an important role in the development of TRAS. Graft function can be preserved with early intervention.
\end{abstract}

Keywords: Allograft dysfunction, hypertension, transplant renal artery stenosis

İletişim kurulacak yazar/Corresponding author: serkanfyalin@yahoo.com

Başvuru/Submitted: 05.04.2019• Revizyon Talebi/Revision Requested: $29.05 .2019 \bullet$

Son Revizyon/Last Revision Received: 29.05.2019• Kabul/Accepted: 21.06.2019• Online Yayın/Published Online: 26.08 .2019

(C) Telif Hakkı $2020 \mathrm{~J}$ Ist Faculty Med - Makale metnine jmed.istanbul.edu.tr web sayfasından ulaşılabilir.

(C) Copyright 2020 by J Ist Faculty Med - Available online at jmed.istanbul.edu.tr 


\section{GiRiş}

Böbrek nakli, son dönem böbrek yetmezliği hastalarına diyaliz tedavilerine göre daha yüksek hayat kalitesi ve daha uzun yaşam sağlar (1). Cerrahi tekniklerin ilerlemesi ile ilerleyen yıllarla birlikte peroperatif komplikasyonlarda belirgin azalma olmuştur (2).

Günümüzde renal transplantasyonla ilişkili vaskuler komplikasyonların \%75 ini transplant renal arter stenozu (TRAS) oluşturur (3). TRAS ve transplant sonrası arteriyel hipertansiyon; allogreft disfonksiyonu ve greft kaybının tedavi edilebilir bir nedenidir. TRAS, böbrek naklinden sonra genellikle 3 ay ila 2 yıl arasında görülür (4). Görülme sıklığı farklı serilerde \%1 ila \%23 arasında değişmektedir (5). TRAS gelişimi ile ilgili risk faktörlerinde vericide renal arter aterosklerozu, alıcıda iliak arter stenozu, donör yaşı, uzun süreli gecikmiş graft fonksiyonu, soğuk iskemi zamanı, kalsinörin toksisitesi, eşlik eden CMV enfeksiyonu ve cerrahi teknik rapor edilmiştir $(5,6)$. Stenoz genellikle cerrahi travma ve postoperatif stenoza bağlı olarak anastomoz bölgesinde görülebilir. Ayrıca alıcıda proksimalde renal arter aterosklerozuna bağlı ve vericide immünolojik veya mekanik faktörlerle ilişkili distal renal arterinde oluşabilir.

Doppler USG görüntülemede renal arter pik sistolik akım hızının $200 \mathrm{~cm} / \mathrm{s}$ daha yüksek olması, renal arter resistif indeksinin 0,5'den daha yüksek olması, stenotik bölge ve prestenotik bölgenin akım gradyentinin 2:1'den yüksek olması ile tanı konur. Kesin tanı anjiografi ile konur (7).

Perkütan Transluminal Anjiyoplasti (PTA) vakaların \%60-90 arasında böbrek reperfüzyonu sağlayarak tedavide başarı sağlamaktadır. Stent implantasyonuna genellikle anjiyoplastiden sonra \%30'dan fazla residüel stenoz olursa ihtiyaç duyulmaktadır (8).

\section{GEREÇ VE YÖNTEM}

Hastanemiz Nefroloji Polikliniğinde 2017 yılında böbrek nakli yapılan ve takip edilen vakalar retrospektif olarak incelendi. TRAS saptanan vakaların yaşı, cinsiyet, bazal kreatinin ve tedavi sonrası kreatinin, ek hastalıkları ve alışkanlıkları gibi demografik özellikleri, transplantasyon verileri ve TRAS ilişkili bulguları kaydedildi.

Böbrek nakli yapılma tarihi ile TRAS tanısına kadar geçen süre ve böbrek fonksiyonları, tanı sırasında ölçülen kan basıncı değerleri kaydedildi Kan basıncı yüksek saptanan hastalara renal doppler USG görüntüleme yapıldı. Şüpheli bulguları olup glomerül filtrasyon hızı (GFH) 30ml/ dk'nın üstünde olan hastalara MR anjiyografi yapldı. MR anjiyografi ile stenoz saptanan TRAS tanılı hastalara PTA ile stent takıldı. İşlem sonrasında kan basıncı kontrolü yaparak kan basıncı değerleri kaydedildi.

Çalışmamız retrospektif bir çalışma olup, verileri 16,0 versiyon SPSS software (SPSS Inc, Chicago, IL) kullanılarak tanımlayıcı istatistikler yapıldı. Değişkenler ortalama standart sapma olarak tanımlandı. Normal dağılım göstermeyen değişkenler medyan (min-maks) olarak tanımlandı.

\section{BULGULAR}

2017 yılında böbrek nakli yapılan vakaların retrospektif olarak izleminde toplam 26 vakanın (11 kadavra, 15 canlı) 6'sında TRAS saptandı.

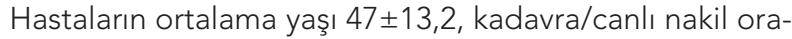
nı 3/3, kadın sayısı 2 idi. Hastaların başvuru bulgusu hipertansiyon olup, ortalama kan basıncı değerleri Sistolik $160 \pm 8,9 \mathrm{mmHg}$, Diyastolik 100 \pm mm Hg idi.

Tüm hastalara indüksiyon tedavisinde ATG, idame tedavisinde Prednizolon+Mikofenolat Mofetil+Takrolimus verilmişti. Kadaverik donörlerde soğuk iskemi zamanı median 244 dk (150-312) idi.

İki hastada (Vaka 2 ve 6) CMV-PCR pozitifti. Üç hasta Tip 1 DM, 1 Hasta Tip 2 DM, 1 hasta Hipertansiyon tanısı ve bir hasta ise etyolojisi bilinmeyen son dönem böbrek yetmezliği nedeniyle böbrek nakli yapılan hastaydı. Olayın gelişme süresi nakilden sonra ortalama 105,6士68,8 gündü. Sadece bir hasta preemptif nakil olup, nakilden önce 4 hasta HD, 1 hasta CAPD tedavisi altındaydı.

Tablo 1: Demografik veriler

\begin{tabular}{|c|c|c|c|c|c|c|c|}
\hline & Yaş & Cinsiyet & $\begin{array}{l}\text { Hipertansiyon } \\
\mathrm{mm} / \mathrm{hg}\end{array}$ & $\begin{array}{c}\text { Ek } \\
\text { hastalıkları }\end{array}$ & $\begin{array}{c}\text { Bazal } \\
\text { kreatinin }\end{array}$ & $\begin{array}{c}\text { Tedavi sonrası } \\
\text { kreatinin }\end{array}$ & Sigara \\
\hline Vaka 1 & 58 & Erkek & $150 / 100$ & $\mathrm{HT}, \mathrm{KAH}$ & 1,47 & 0,7 & Var \\
\hline Vaka 2 & 48 & Erkek & $160 / 100$ & $\mathrm{KAH}, \mathrm{DM}$ & 2,24 & 0,7 & Yok \\
\hline Vaka 3 & 25 & Kadın & $170 / 90$ & $H T, D M$ & 2,41 & 0,8 & Var \\
\hline Vaka 4 & 39 & Kadın & $170 / 100$ & $H T, D M$ & 2,55 & 0,9 & Yok \\
\hline Vaka 5 & 55 & Erkek & $150 / 100$ & $H T, D M$ & 2,74 & 1,6 & Var \\
\hline Vaka 6 & 59 & Erkek & $160 / 100$ & $\mathrm{HT}$ & 3,01 & 0,9 & Yok \\
\hline
\end{tabular}

KAH: Koroner arter hastalığı, HT: Hipertansiyon, DM: Diabetes Mellitus 
Tablo 2: Böbrek nakli ile ilişkili bulgular.

\begin{tabular}{lccccccc}
\hline & Nakil türü & $\begin{array}{c}\text { Öncesindeki } \\
\text { RRT }\end{array}$ & $\begin{array}{c}\text { HLA } \\
\text { uyumu }\end{array}$ & $\begin{array}{c}\text { Olayın gelişme } \\
\text { süresi }\end{array}$ & $\begin{array}{c}\text { Soğuk iskemi } \\
\text { zamanı }\end{array}$ & $\begin{array}{c}\text { SDBH } \\
\text { etyoloji }\end{array}$ & Idame tedavi \\
Vaka 1 & Kadavra & 10 Yıl HD & $4 / 6$ & 124. gün & $312 \mathrm{dk}$ & Unknown & DC+MMF+Tacrolımus \\
Vaka 2 & Kadavra & 13 Yll CAPD & $2 / 6$ & 221. gün & $186 \mathrm{dk}$ & Tip 1 DM & DC+MMF+Tacrolımus \\
Vaka 3 & Kadavra & 2 Yıl HD & $0 / 6$ & 112. gün & $235 \mathrm{dk}$ & HT & DC+MMF+Tacrolımus \\
Vaka 4 & Canlı & 4 Ay HD & $3 / 6$ & 107. gün & - & Tip 1 DM & DC+MMF+Tacrolımus \\
Vaka 5 & Canlı & 5 Ay HD & $1 / 6$ & 35. gün & - & Tip 1 DM & DC+MMF+Tacrolımus \\
Vaka 6 & Canlı & Preemptif & 0/6 & 37. gün & - & Tip 2 DM & DC+MMF+Tacrolımus \\
\hline
\end{tabular}

RRT: Renal Replasman Tedavisi, HD: Hemodiyaliz, CAPD: Sürekli Ambulatuvar Periton Diyalizi, SDBH: Son Dönem Böbrek Hastalığı DC: Deltacortril, MMF: Mikofenolat Mofetil

Hastaların demografik özellikleri Tablo 1'de, son dönem böbrek yetmezliği tedavileri ve böbrek nakline ilişkin veriler Tablo 2'de özetlenmiștir.

Tüm vakalar böbrek nakli sonrasında gelişen hipertansiyon ve akut allograft disfonksiyonu ile başvurdu. Renal Doppler USG incelemesi şüpheli olan vakalarda transplant renal arter ve iliak artere yönelik MR anjiyografi yapıldı. Stenoz saptanan vakalara PTA yapılarak stent takıldı.

iki hastada MR anjiyografide transplant renal arter ile eş zamanlı iliak arterlerde de stenoz görülerek işlem sırasında iliak artelere de stent takıldı. (Vaka 2 ve 6) (Resim 1a, 1b)

Bir hastanın 2 seans hemodiyaliz ihtiyacı oldu. Hastalara stent işlemi sonrası klopidogrel ve aspirin başlandı.
Takiplerinde hastaların antihipertansif ihtiyacı azaldı. Iş̧lem sonrası hastaların kan basıncı değerleri sistolik $112 \pm 7,5 \mathrm{mmHg}$; diastolik $77 \pm 11,4 \mathrm{mmHg}$ idi. Hastalar halen ayaktan takip polikliniğinde izlenmektedir.

\section{TARTIŞMA}

Literatürde izlenen çalışmalarda böbrek nakli sonrasında renal arter stenozu gelişme sıklı̆ı \%1 ile \%23 arasında değişmektedir (5). Çeşitli çalışmalarda izlenen bu farklıı̆ın sebebi hastalardaki diyabet mellitus, hipertansiyon, dislipidemi, ve sigara gibi ek risk faktörlerinin değişkenliğine bağlı olabileceği düşünülmüştür. Hastanemiz organ nakli biriminde bir yıl içinde yapılan 26 böbrek nakli olgusunun 6'sında TRAS saptandı. TRAS oranını literatür bulgularına göre üst sınırda \%23 olarak bulduk. TRAS oranının üst sınır
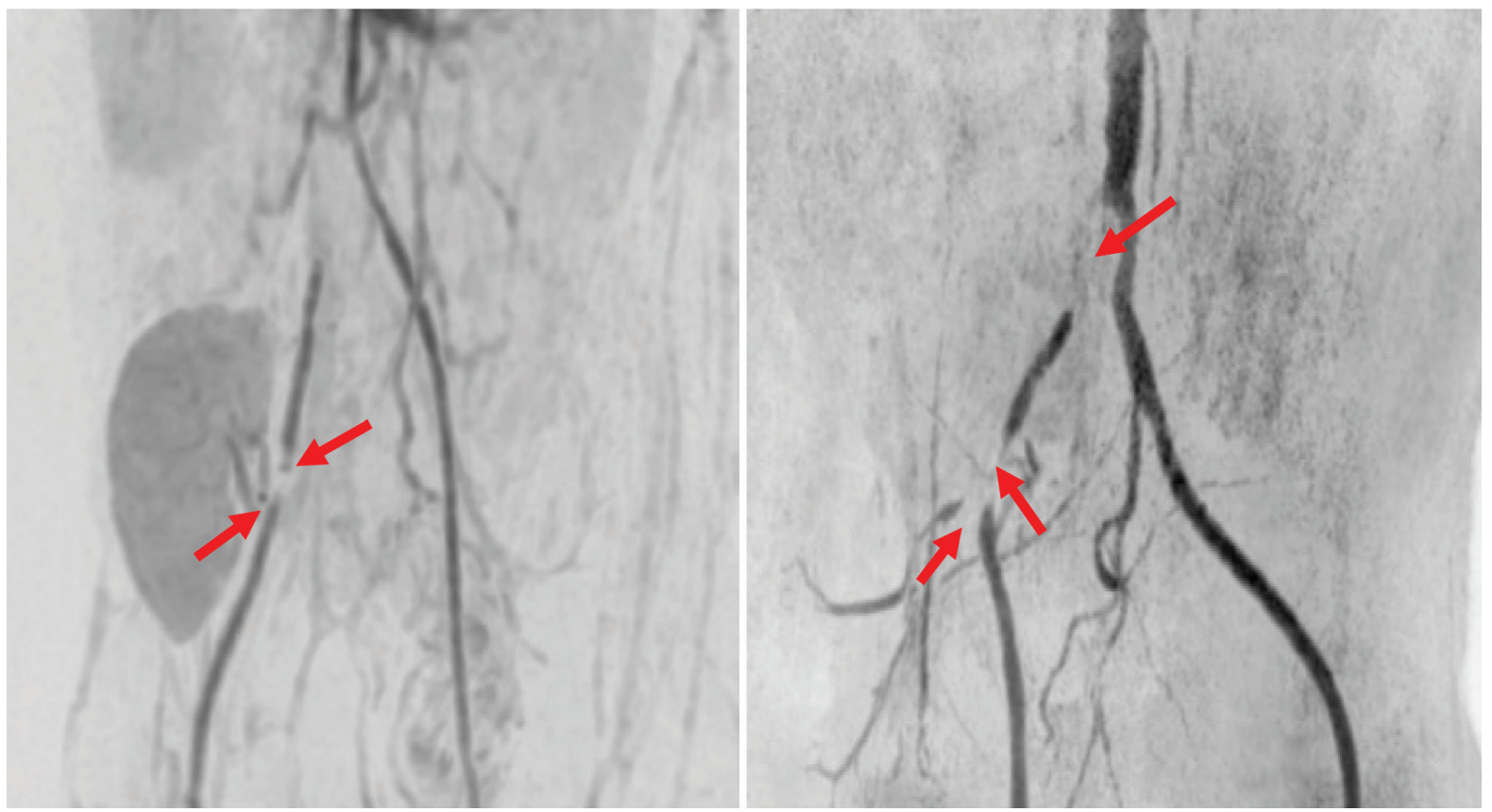

Resim 1a, 1b: Vaka 2 ve 6: Illiak Arter ve Transplant Renal Arter Stenozu Birlikteliği. 

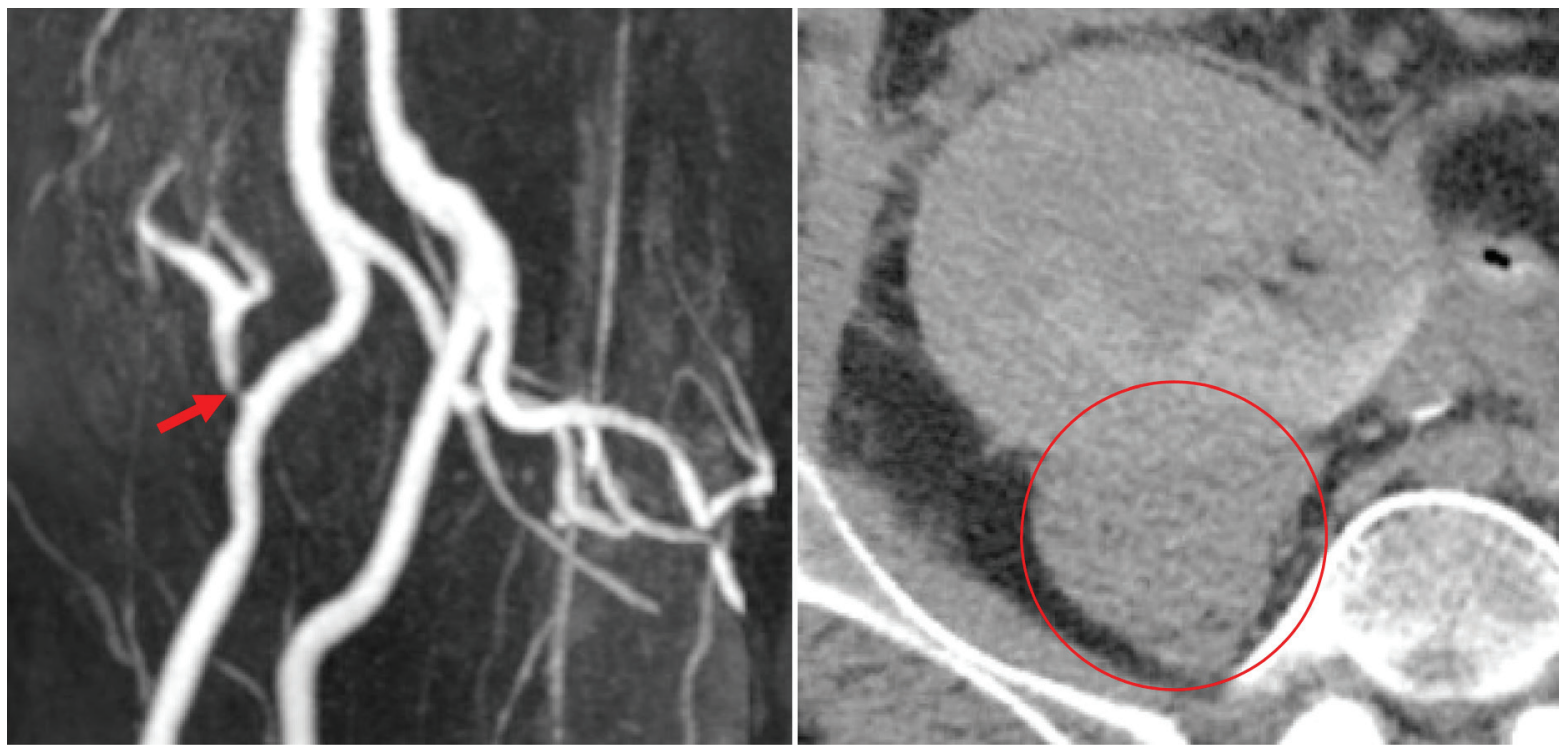

Resim 2a, 2b: Vaka 5: Transplant Renal Arter Stenozu ve İşlem Sonrası Gelişen Page Böbrek.

sıklıkta olmasının nedeni hastaların tümünde ateroksleroza eğilim yaratacak diyabet ve hipertansiyon gibi ek hastalıkların ve sigara alışkanlığının olması ile ilişkilendirildi.

TRAS'Iı hastaların demografik özellikleri ve renal transplantasyon özellikleri literatürle uyumlu idi. 58 kontrol böbrek nakilli hastaya karşıık TRAS'|ı 29 hastanın incelendiği retrospektif bir çalışmada gecikmiş graft fonksiyonu ve CMV pozitifliğinin artmış TRAS riski ile ilişkili olduğu saptandı (6). Bizim hastalarımızdan 2'sinde CMV pozitifliği vardı. Renal arter stenozuna eşlik eden iliak arter stenozu varlığı CMV PCR (+) olan iki hastada görüldü. İmmünsuprese hastalarda bilinen risk faktörlerine ilave olarak gelişecek $\mathrm{CMV}$ enfeksiyonu olayın şiddetini ve dağılımını artıran bir faktör olabilir.

TRAS tanısında MR ve CT görüntüleme ile tanı koyma sıklığı giderek artmaktadır. Bu çalışmada yer alan hastaların tanısı da MR anjiyo görüntüleme yöntemi ile yapılmışır.

TRAS nedeniyle yapılan PTA sonrası anevrizma, diseksiyon kanama gibi komplikasyonlar görülebilir. Literatürde, PTA sonrası postoperatif komplikasyonları içeren 26 çalışmanın incelendiği bir meta analizde TRAS sonrası genel komplikasyon oranı \%9 bulunmuştur (8). Bu komplikasyonların çoğunluğu ek müdahale gerektirmeyen spontan gerileyen komplikasyonlardır. Hastalarımızdan birinde (Vaka 5) PTA işlemi sonrasında Page böbrek (böbrek kapsül altına olan kanama ile oluşan mekanik bası sonucunda gelişen hipertansiyon) görüldü. Takiplerde bu olayın kendiliğinden düzeldiği görüldü (Resim 2a, 2b).

TRAS, böbrek naklinden sonra gelişen allograft disfonksiyonunda akut humoral rejeksiyon ve enfeksiyonlar ile birlikte ilk akla gelen sebeplerden biridir. Diğer risk faktör- leri ile birlikte cerrahi teknik gelişiminde önemli rol oynar. Erken tanı ve tedavi ile greft fonksiyonu korunabilmektedir (9). Hipertansiyon ve bozulmuş greft fonksiyonu ile başvuran hastalarda böbrek naklinden önce uzun dönem hemodiyalize girenler, diyabet mellitus tanısı olanlar ,ve ateroskleroz için yüksek risk taşıyan hastalarda iliak arter stenozu da akla getirilmelidir ve bu hastaların iliak arter görüntülemeleri de yapılmalıdır.

Vakalarımızın ikisinde CMV pozitifliği ile birlikte iliyak arter stenozu da görüldü. Bu durum CMV pozitif hastalarda stenoz riski artışı nedeniyle daha ayrıntılı incelemeyi gerektirebilir. Ayrıca bu grupta yer alan hastalara nakil öncesi değerlendirmelerinde de iliyak arter görüntülemelerinin de yapılması yararlı olabilir.

Etik Komite Onayı: Retrospektif çalışma olduğundan etik komite onayı alınmamıştır.

Bilgilendirilmiş Onam: Retrospektif bir çalışma olduğundan bilgilendirilmiş onam alınmamıştır.

Hakem Değerlendirmesi: Dış bağımsız.

Yazar Katkıları: Çalışma Konsepti/Tasarım- A.B.H., S.F.Y., Z.B.B., M.M.; Veri Toplama- S.F.Y., Ç.Ö.A.; Veri Analizi/Yorumlama- E.P.; Yazı Taslağı- A.B.H., P.Ö., Ç.Ö.A., S.Y.; İçeriğin Eleştirel İncelemesi- S.F.Y., Z.B.B., E.P., M.M.; Son Onay ve Sorumluluk- A.B.H., S.Y., P.Ö., Ç.Ö.A., E.P., M.M., S.F.Y., Z.B.B.

Çıkar Çatışması: Yazarlar çıkar çatışması beyan etmemişlerdir.

Finansal Destek: Yazarlar finansal destek beyan etmemişlerdir. 
Ethics Committee Approval: Ethics committee approval was not received due to the retrospective nature of the study.

Informed Consent: Informed consent was not received due to the retrospective nature of the study.

Peer Review: Externally peer-reviewed.

Author Contributions: Conception/Design of Study A.B.H., S.F.Y., Z.B.B., M.M.; Data Acquisition- S.F.Y., Ç.Ö.A.; Data Analysis/Interpretation- E.P.; Drafting Manuscript- A.B.H., P.Ö., Ç.Ö.A., S.Y.; Critical Revision of Manuscript- S.F.Y., Z.B.B., E.P., M.M.; Final Approval and Accountability- A.B.H., S.Y., P.Ö., Ç.Ö.A., E.P., M.M., S.F.Y., Z.B.B.

Conflict of Interest: Authors declared no conflict of interest.

Financial Disclosure: Authors declared no financial support.

\section{KAYNAKLAR}

1. Suthanthiran M, Strom TB. Renal transplantation. N Engl J Med 1994;331(6):365-76. [CrossRef]

2. Haberal M, Boyvat F, Akdur A, Kırnap M, Özçelik Ü, Yarbuğ Karakayalı F. Surgical complications after kidney transplantation. Exp Clin Transplant 2016;14(6):587-95.
3. Agüera Fernández LG, Zudaire JJ, Isa WA, Sánchez de la Muela PL, Rosell D, de Castro F, et al. Vascular complications in 237 recipients of renal transplant from cadaver. Actas Urol Esp 1992;16(4):292-5.

4. Bruno S, Remuzzi G, Ruggenenti P. Transplant renal artery stenosis. J Am Soc Nephrol 2004;15(1):134-41. [CrossRef]

5. Audard V, Matignon M, Hemery F, Snanoudj R, Desgranges $\mathrm{P}$, Anglade $\mathrm{MC}$, et al. Risk factors and long-term outcome of transplant renal artery stenosis in adult recipients after treatment by percutaneous transluminal angioplasty. Am J Transplant 2006;6(1):95-9. [CrossRef]

6. Pouria S, State Ol, Wong W, Hendry BM. CMV infection is associated with transplant renal artery stenosis. QJM. 1998;91(3):185-9. [CrossRef]

7. Bruno S, Remuzzi G, Ruggenenti P. Transplant renal artery stenosis. J Am Soc Nephrol 2004;15(1):134-41. [CrossRef]

8. Humar A, Matas AJ. Surgical complications after kidney transplantation. Semin Dial 2005;18(6):505-10. [CrossRef]

9. Chen W, Kayler LK, Zand MS, Muttana R, Chernyak V, DeBoccardo GO. Transplant renal artery stenosis: clinical manifestations, diagnosis and therapy. Clin Kidney J 2015;8(1):71-8. [CrossRef] 